\title{
Variability of Exostoses on Human Jaws During the Past Six Millennia in Northern China
}

\author{
Variabilidad de las Exostosis en las Mandíbulas Humanas Durante \\ los Últimos Seis Milenios en el Norte de China
}

\author{
Ting Kang ${ }^{1,2,3}$; Yujia Kong ${ }^{4}$ X Xuepeng Chen ${ }^{1,2}$; Shiyou Huang ${ }^{5}$ \& Jinling Shao ${ }^{3}$
}

\begin{abstract}
KANG, T.; KONG, Y.; CHEN, X.; HUANG, S. \& SHAO, J. Variability of exostoses on human jaws during the past six millennia in northern China. Int. J. Morphol., 39(5):1311-1315, 2021.

SUMMARY: The aim of this study was to survey oral exostoses in human populations that belonged to the same region encompassing five periods over 6000 years, to determine the prevalence and its changing trend over time. A total of 306 human jaws belonging to the modern Xi'an region and four archeological sites, Banpo (6700-5600 years BP), Shaolingyuan (3000 years BP), Shanren (2200 years BP) and Chang' an (1000-1300 years BP), were investigated. The degree of buccal exostosis (BE), torus mandibularis (TM) and torus palatinus (TP) and the TP shape were recorded. The prevalence of BE, TM, and TP in the five groups was $20.8 \%-62.5 \%, 17.5$ $\%-71.5 \%$, and $31.7 \%-74.2 \%$, respectively. The differences in the three types of exostoses among the five groups were all statistically significant, but only TM and TP showed a decreasing trend over time. A high and quite diverse prevalence of oral exostoses was found in the five groups of samples. Decreasing trends in relation to time for TM and TP were detected.
\end{abstract}

KEY WORDS: Buccal exostosis; Torus mandibularis; Torus palatinus; Ancient populations; China.

\section{INTRODUCTION}

Oral exostoses, which are known as tori or hyperostoses, are benign bony enlargements that yield no symptoms. Instead of pathological conditions, these structures are considered to be normal anatomical variations that consist of a limited quantity of bone marrow and a dense cortex (Dou et al.,2017). According to the location, oral exostosis is commonly called torus mandibularis (TM) when it appears on the lingual surface of the mandible, torus palatinus (TP) when it appears along the midline of the hard palate, and buccal exostosis (BE) when it appears on the buccal alveolar region of the maxilla

The prevalence of oral exostoses varies widely between different ethnic groups: from $0-48.0 \%$ for BE, from 0-64.4\% for TM, and 0.54\%-64.4\% for TM (Chiang et al., 2014; AlZarea, 2016). Most previous studies of oral exostoses have investigated the prevalence and assessed the association between oral exostoses and related pathogenic factors within a certain population or have compared the prevalence in multiple populations from different sites during the same period. However, few studies have investigated samples from one site that spans several chronologic ranges. A comparative analysis of the nonmetric variation in oral exostoses of historical populations from the same region can not only accumulate valuable archeological information on the morphology of the human jaws but also explore the temporal trends of oral exostoses, which may help to illustrate its etiology.

In this study, we surveyed the skeletons of ancient populations from four archeological sites of Xi'an in northern China and from the modern population living in the same location (Fig. 1). Among these sites, the Banpo site (approximately 6700-5600 years BP) is a typical Neolithic matriarchal community of the heyday Yangshao culture in the Yellow River basin that used polished stone tools for farming, fishing, hunting and a small amount of

\footnotetext{
${ }^{1}$ Department of Orthodontics, The Affiliated Stomatology Hospital, Zhejiang University School of Medicine, Hangzhou, Zhejiang, P.R. China.

${ }^{2}$ Key Laboratory of Oral Biomedical Research of Zhejiang Province, Hangzhou, Zhejiang, P.R. China.

${ }^{3}$ Department of Orthodontics, School of Stomatology, The Air Force Medical University, Xi' an, Shannxi, P. R. China.

${ }^{4}$ Department of Public Health and Management, Weifang Medical University, Weifang, Shandong, P. R. China.

${ }^{5}$ Great dental clinic, Hangzhou, P. R. China.

This work was supported by Natural Science Foundation of Zhejiang Province (No. LY18H0001).
} 


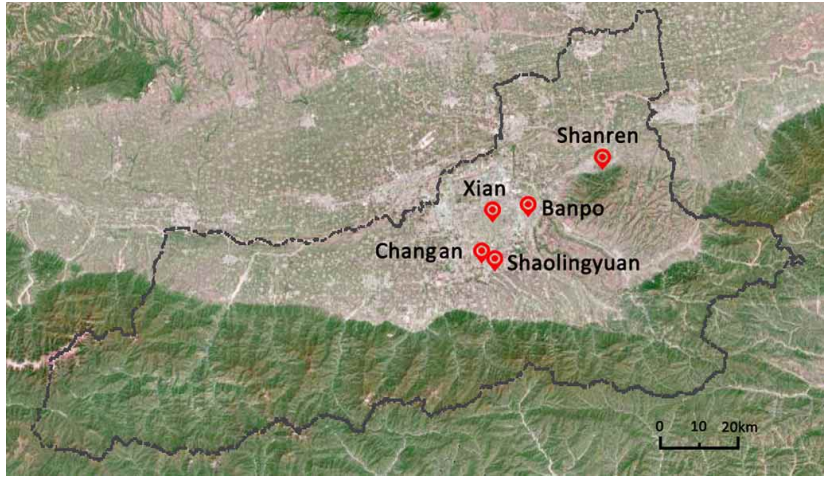

Fig. 1. Map of Xi' an, showing the locations of the four archeological sites.

livestock husbandry to survive, while millet was the main food . The Shaolingyuan site (approximately 3000 years BP) belonged to the western Zhou era (Huang et al., 2012). Although agriculture and livestock husbandry had improved at that time, the production of grains as the main food was still insufficient, and consequently, fishing, hunting and gathering were still necessary for survival. During this period, grain processing was accomplished with simple tools such as the stone millstone, stone mill, mortar and pestle. Until the Qin Dynasty (the Shanren kiln site, approximately 2200 years BP), food was mainly obtained from farming and animal husbandry, but the phytolith analysis showed that the food was still rough in texture . The Chang' an site (approximately 1100-1300 years BP) belonged to the Tang Dynasty, where food was abundant and food preparation was more advanced.

The present study focused on the oral exostoses of these four ancient populations and of modern populations from northern China to determine the prevalence of these nonmetric traits of jaws and its changing trend over time, in order to illustrate the relationship between oral exostoses and predisposing factors based on archeological background evidence.

\section{MATERIAL AND METHOD}

Samples. The Banpo Museum in Xi'an provided jaws from the Banpo site, which was composed of three relatively integrated communal villages located in the Chanhe River basin. The jaws from the Shaolingyuan site, Shanren site and Chang'an site were provided by the Shaanxi Provincial Institute of Archaeology. The dry jaw bones of the modern population were provided by the anatomy department of Air Force Medical University in $\mathrm{Xi}$ ' an. The five groups of samples described above were collected, and relatively intact samples were selected.

In total, 306 jaws were investigated. Among these jaws, 83 were from the Banpo site; 50 were from the Shaolingyuan site; 58 were from the Shanren site; 55 were from the Chang' an site; and 60 were from modern humans in Xi'an.

Evaluation of oral exostoses. The existence of exostoses was recorded at three locations on each jaw. The buccal or labial aspect of the maxillary alveolar process was recorded for $\mathrm{BE}$; the lingual side of the mandibular alveolar process was recorded for TM; and the midline of the hard palate was recorded for TP.

For BE and TM, each side is observed and recorded separately. To facilitate analysis, the degree of BE and TP was scored as mild (0-3 mm), moderate $(3-5 \mathrm{~mm})$ or severe $(\geq 5 \mathrm{~mm})$ according to the base-to-peak height (Woo, 1950), and the degree of TM was scored as mild (0-3 mm), moderate $(3-6 \mathrm{~mm})$ or severe $(\geq 6 \mathrm{~mm})$ according to the base-to-peak height (Reichart et al., 1988). In addition, the TP shape was classified into three shapes: carinated, mounded and warty (Wu et al., 1984). A carinated shape refers to a narrow and long bony ridge with the same overall width (Fig. 2A). A mounded shape
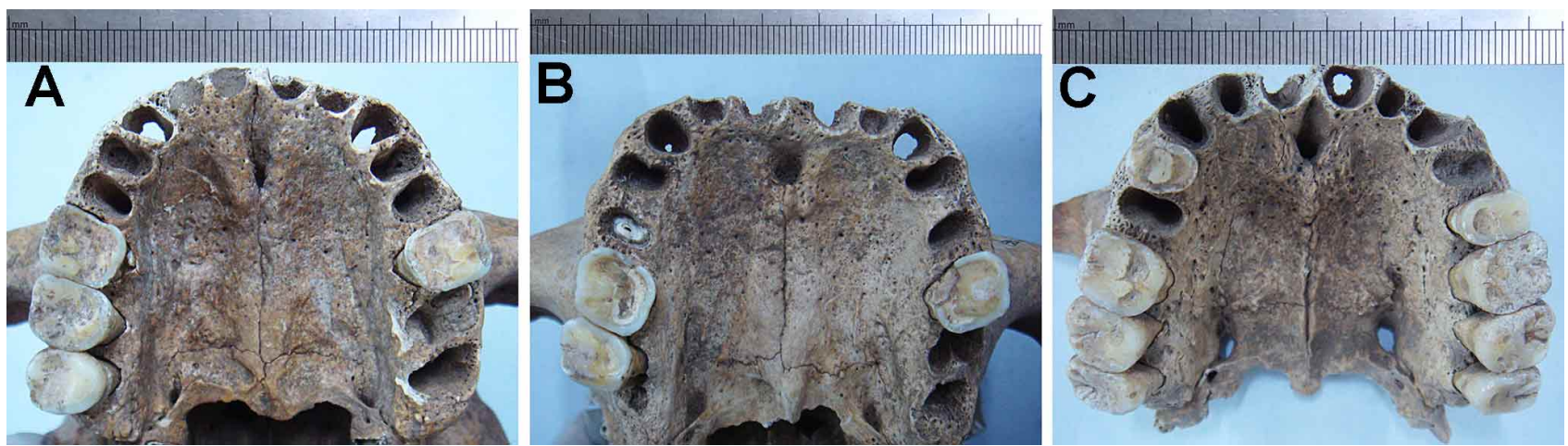

Fig. 2. Shape of torus palatinus (TP): carinated (A), mounded (B), warty (C). 
refers to a torus that is wider in the middle and sharper at both ends (Fig. 2B). A warty shape refers to any other irregular exostoses (Fig. 2C). To avoid observational errors, all the exostoses were surveyed by one examiner under constant light.

Statistical analysis. No significant difference was found in the occurrence of BE or TM on the bilateral sides of the samples $(\mathrm{P}>0.05)$, so the observation results from both sides were combined before analysis. The proportion and number of counting data were determined. Pearson's chi-square test was used to compare proportions among different subgroups. Fisher's exact test was used when more than $20 \%$ of cells had less than 5 expected count numbers. Most tests met a power level of $70 \%$ or higher. Hypothesis testing was two-sided with a statistical significance level of 0.05 . All data were handled and analyzed using SAS version 9.3 (SAS Institute, Cary, NC).

\section{RESULTS}

In 612 subjects studied, 213 BEs, 226 TMs and 116 TPs were identified. The degree of the three types of exostoses and the TP shape are shown in Table I.

Morphologically, mild BEs were mainly located on the buccal alveolar crest of the molars, while a few were located in the area of the canines and premolars (Fig. 3A). Moderate to severe BEs were often continuous bony ridges with a uniform thickness or ripple shape along the alveolar process of the posterior tooth at the level of the horizontally absorbed alveolar bone (Fig. 3B,C). Unlike the morphology of BE, that of mild TM was characterized by 1 to 3 peashaped nodules, most of which were located in the premolar area and rarely were located in the canine or even incisor area (Fig. 4A). Moderate to severe TM manifested as multiple globular exostoses, a continuous bony ridge, or a
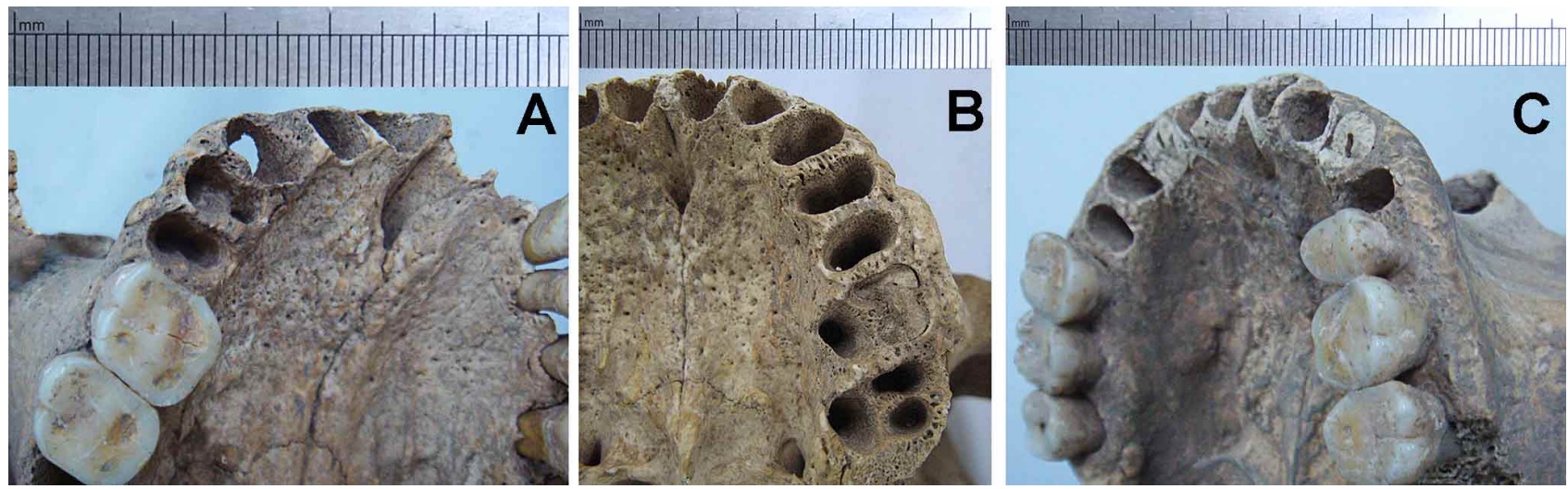

Fig. 3. Buccal exostosis (BE): mild (A), moderate (B), severe (C).

Table I. Three types of oral exostoses in the five populations (n (\%)).

\begin{tabular}{lcccccc}
\hline & & Banpo & Shaolingyuan & Shanren & Chang'an & Xi'an \\
\hline BE & Mild & $60(46.9)$ & $10(18.9)$ & $12(21.1)$ & $24(26.1)$ & $38(31.7)$ \\
& Moderate & $17(13.3)$ & $1(1.9)$ & $0(0.0)$ & $23(25.0)$ & $15(12.5)$ \\
& Severe & $3(2.3)$ & $0(0.0)$ & $0(0.0)$ & $3(3.3)$ & $7(5.8)$ \\
Total $a$ & $450(100.0)^{b}$ & $128(28.4)$ & $53(11.8)$ & $57(12.7)$ & $92(20.4)$ & $120(26.7)$ \\
TM & Mild & $59(43.1)$ & $37(42.5)$ & $22(20.0)$ & $24(33.3)$ & $16(13.3)$ \\
& Moderate & $37(27.0)$ & $13(14.9)$ & $0(0.0)$ & $8(11.1)$ & $5(4.2)$ \\
& Severe & $2(1.5)$ & $0(0.0)$ & $0(0.0)$ & $3(4.2)$ & $0(0.0)$ \\
Total $a$ & 526(100.0 $)^{b}$ & $137(26.0)$ & $87(16.5)$ & $110(20.9)$ & $72(13.7)$ & $120(22.8)$ \\
TP-Degree & Mild & $27(40.3)$ & $19(61.3)$ & $19(61.3)$ & $21(50.0)$ & $19(31.7)$ \\
& Moderate & $3(4.5)$ & $4(12.9)$ & $2(6.5)$ & $1(2.4)$ & $0(0.0)$ \\
& Severe & $1(1.5)$ & $0(0.0)$ & $0(0.0)$ & $0(0.0)$ & $0(0.0)$ \\
Total $a$ & 231) & $67(29.0)$ & $31(13.4)$ & $31(13.4)$ & $42(18.2)$ & $60(26.0)$ \\
TP Shape & Carinated & $7(10.4)$ & $5(16.1)$ & $2(6.5)$ & $2(4.8)$ & $11(3.0)$ \\
& Mounded & $16(23.9)$ & $8(25.8)$ & $7(22.6)$ & $4(9.5)$ & $3(8.3)$ \\
& Warty & $8(11.9)$ & $19(61.3)$ & & $3(5.0)$ \\
\hline
\end{tabular}


prominent hemispherical torus in the premolar and molar areas (Fig. 4B-D). The morphology of TP was more complicated than that of the first two types. These tori usually started from the lingual aspect of the incisors or the posterior edge of the incisive foramina. The milder TPs morphed into a flat shape at the mesial line of the bilateral first molars; the more severe TPs continued to the line of the bilateral palatal foramen. Generally, carinated TP was narrower; mounded TP was thicker in the front third and wider and thinner in the middle, with a thickened rear end that formed a pointed tail; warty TP, which was similar to the former two types, was more variable and could be accompanied by short bead-like bony nodules or interruptions.

The variability of these three types of oral exostoses in the five groups of samples is illustrated in Table II. The differences among the five groups of samples were all statistically significant, but only TM and the degree of TP showed a decreasing trend over time, while the decreasing trend of TM was more obvious than that of TP.

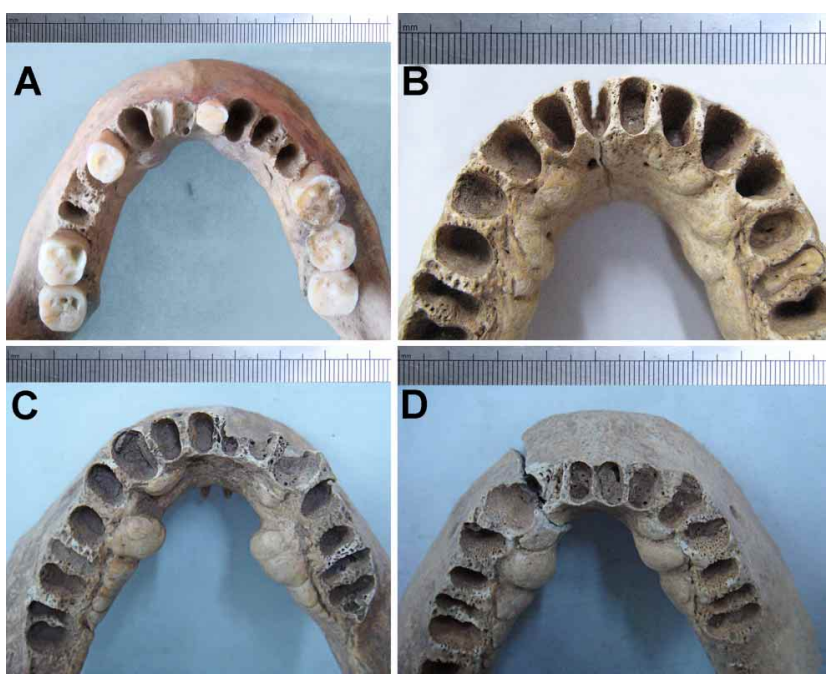

Fig. 4. Torus mandibularis (TM): mild (A), moderate (B), severe (C, D).

Table II. Comparison of oral exostoses between the five group of samples.

\begin{tabular}{lllrc}
\hline & $X^{2}$ & $P a$ & $Q$ & \multicolumn{1}{c}{$P b$} \\
\hline BE & 66.569 & $<0.001^{* *}$ & 0.042 & 0.379 \\
TM & 131.421 & $<0.001^{* *}$ & -0.365 & $<0.001^{* *}$ \\
TP-Degree & 27.256 & $0.007^{* *}$ & -0.167 & \\
TP Shape & 30.246 & $0.003^{* *}$ & - & -
\end{tabular}

a Pearson Chi-Square with Fisher exact test. b Spearman correlation test. Two-sided test with significance level $\mathrm{a}=0.05$. $* \mathrm{P}<0.05$. $* * \mathrm{P}<0.01$.

\section{DISCUSSION}

In this study, we investigated three types of oral exostoses in ancient and modern populations from the same region in northern China to identify whether the presence of oral exostoses is related to time. The findings indicated that the prevalence is high and quite diverse. Moreover, the analytic results demonstrated that decreasing trends in relation to time for TM and TP occurred between the five groups of samples from five populations.

Frequencies of oral exostoses were found to be high and quite diverse in the five groups of samples (from $4.1 \%$ to $74.2 \%$ ) (Table II). Previous literature has revealed that the prevalence of oral exostoses varies markedly between different ethnic groups, with a higher prevalence in Asian and even Chinese populations (Sathya et al., 2012; Hsu et al., 2016). Generally, BE occurs in 34.1-48.0 \%, TM in 4.6 to $24.2 \%$, and TP in $17.9 \%$ to $31 \%$ of the Chinese population (Pechenkina \& Benfer, 2002; Sathya et al.; Chiang et al.; Kumar Singh et al., 2017). In this study, the prevalence of BE, TM, and TP in the five groups was 20.8 $\%-62.5 \%, 17.5 \%-71.5 \%$, and $31.7 \%-74.2 \%$, respectively, with a wide range of variation, which is similar to the findings in the literature above.

The present analysis showed a decreasing trend of the degree of TM and TP over time, while BE did not show an increasing or decreasing trend, although the differences between the five groups of samples were all significant. This means that the changes in etiology of TM and TP somewhat differed from those of BE during the past 6,000 years. The etiology of oral exostoses is thought to be an interplay of genetic and environmental factors (Gorsky et al., 1996; Oualalou et al., 2014). Environmental stress must reach a certain threshold level before a genetically predisposed individual develops the trait (Pechenkina \& Benfer). Unfortunately, longitudinal studies on change trends in exostoses over a large temporal range are very limited. The subjects in this study all lived in northern China. Although they shared similar genes, the diet and living environment have changed greatly over the past 6 millennia. The Banpo population consisted of hunter-gatherers (Yeh \& Mitchell, 2016). Previously, Meng et al. (2011) of our research team found uneven wear of the anterior and posterior teeth of Banpo people, indicating the existence of extramasticatory activities. From the western Zhou era (Shaolingyuan population) and Qin Dynasty (Shanren population) to the Tang Dynasty (Chang'an population), the hunter-gatherer economy began to transform to an intensive agricultural economy, which resulted in a difference in oral health status (Lee et al., 2019). The increase in farm products and 
improved food processing methods made food easier to chew, resulting in progressively weaker muscles and less masticatory force. Muscle activity and masticatory force are considered to be important environmental factors of exostoses (Palm et al., 2014; Yoshinaka et al., 2014; Jeong et al., 2018), which may explain the decreasing trend with time.

In conclusion, a high and quite diverse prevalence of oral exostoses was found in the five groups of samples from northern China during the past 6,000 years. Decreasing trends in relation to time for TM and TP were detected. Based on archeological background evidence, diet and masticatory stress may be responsible for these changes, and further studies on oral health indicators in the same populations will help to elucidate the occurrence of exostoses.

KANG, T.; KONG, Y.; CHEN, X.; HUANG, S. \& SHAO, J. Variabilidad de las exostosis en las mandíbulas humanas durante los últimos seis milenios en el norte de China. Int. J. Morphol., 39(5):13111315, 2021.

RESUMEN: El objetivo de este estudio fue sondear las exostosis orales en poblaciones humanas que pertenecían a la misma región abarcando cinco períodos durante 6000 años, para determinar la prevalencia y su tendencia cambiante a lo largo del tiempo. Un total de 306 mandíbulas humanas pertenecientes a la moderna región de Xi'an y cuatro sitios arqueológicos, Banpo (6700-5600 años AP), Shaolingyuan (3000 años AP), Shanren (2200 años AP) y Chang'an (1000-1300 años AP) BP), fueron investigados. Se registró el grado de exostosis bucal (EO), torus mandibular (TM) y torus palatino (TP) y la forma de TP. La prevalencia de EO, TM y TP en los cinco grupos fue $20,8 \%-62,5 \%, 17,5 \%-71,5 \%$ y $31,7 \%-74,2 \%$, respectivamente. Las diferencias en los tres tipos de exostosis entre los cinco grupos fueron todas estadísticamente significativas, pero solo TM y TP mostraron una tendencia decreciente con el tiempo. Se encontró una prevalencia alta y bastante diversa de exostosis oral en los cinco grupos de muestras. Se detectaron tendencias decrecientes en relación al tiempo para TM y TP.

PALABRAS CLAVE: Exostosis bucal; Torus mandibular; Torus palatino; Poblaciones antiguas; Porcelana.

\section{REFERENCES}

AlZarea, B. K. Prevalence and pattern of torus palatinus and torus mandibularis among edentulous patients of Saudi Arabia. Clin. Interv. Aging., 11:209-13, 2016.

Chiang, M. L.; Hsieh, Y. J.; Tseng, Y. L.; Lin, J. R. \& Chiang, C. P. Oral mucosal lesions and developmental anomalies in dental patients of a teaching hospital in Northern Taiwan. J. Dent. Sci., 9(1):69-77, 2014.

Dou, X. W.; Park, W.; Lee, S.; Zhang, Q. Z.; Carrasco, L. R. \& Le, A. D. Loss of Notch3 signaling enhances osteogenesis of mesenchymal stem cells from mandibular torus. J. Dent. Res., 96(3):347-54, 2017.
Gorsky, M.; Raviv, M.; Kfir, E. \& Moskona, D. Prevalence of torus palatinus in a population of young and adult Israelis. Arch. Oral Biol., 41(6):623$5,1996$.

Hsu, C. L.; Hsu, C. W.; Chang, P. C.; Huang, W. H.; Weng, C. H.; Yang, H. Y.; Liu, S. H.; Chen, K. H.; Weng, S. M.; Chang, C. C.; et al. Oral tori in chronic peritoneal dialysis patients. PLoS One, 11(6):e0156988, 2016.

Huang, S.; Kang, T.; Liu, D.; Duan, Y. \& Shao, J. Variability in permanent tooth size of three ancient populations in Xi'an, Northern China. Arch. Oral Biol., 57(11):1467-73, 2012.

Jeong, C. W.; Kim, K. H.; Jang, H. W.; Kim, H. S. \& Huh, J. K. The relationship between oral tori and bite force. Cranio, 37(4):246-53, 2018.

Kumar Singh, A.; Sulugodu Ramachandra, S.; Arora, S.; Dicksit, D. D.; Kalyan, C. G. \& Singh, P. Prevalence of oral tori and exostosis in Malaysian population - A cross-sectional study. J. Oral Biol. Craniofac. Res., 7(3):158-60, 2017.

Lee, H.; Hong, J. H.; Hong, Y.; Shin, D. H. \& Slepchenko, S. Caries, antemortem tooth loss and tooth wear observed in indigenous peoples and Russian settlers of 16th to 19th century West Siberia. Arch. Oral Biol., 98:176-81, 2019.

Meng, Y.; Zhang, H.; Pan, F.; He, Z.; Shao, J. \& Ding, Y. Prevalence of dental caries and tooth wear in a Neolithic population $(6700-5600$ years BP) from northern China. Arch. Oral Biol., 56(11):1424-35, 2011.

Oualalou, Y.; Azaroual, M. F.; Zaoui, F.; Chbicheb, S. \& Berrada, S. Prevalence and clinical characteristics of oral bony outgrowth in a Moroccan population. Rev. Stomatol. Chir. Maxillofac. Chir. Orale, 115(5):268-73, 2014

Palm, E.; Franklin, K. A. \& Marklund, M. Mandibular tori size is related to obstructive sleep apnea and treatment success with an oral appliance. Sleep Breath., 18(2):431-8, 2014.

Pechenkina, E. A. \& Benfer, R. A. The role of occlusal stress and gingival infection in the formation of exostoses on mandible and maxilla from Neolithic China. Homo, 53(2):112-30, 2002.

Reichart, P. A.; Neuhaus, F. \& Sookasem, M. Prevalence of torus palatinus and torus mandibularis in Germans and Thai. Community Dent. Oral Epidemiol., 16(1):61-4, 1988.

Sathya, K.; Kanneppady, S. K. \& Arishiya, T. Prevalence and clinical characteristics of oral tori among outpatients in Northern Malaysia. $J$. Oral Biol. Craniofac. Res., 2(1):15-9, 2012.

Woo, J. K. Torus palatinus. Am. J. Phys. Anthropol., 8(1):81-111, 1950.

Wu, R.; Wu, X. \& Zhang, Z. Anthropometric Methods (in Chinese). Beijing, Science Press, 1984.

Yeh, H. Y. \& Mitchell, P. D. Ancient human parasites in ethnic Chinese populations. Korean J. Parasitol., 54(5):565-72, 2016.

Yoshinaka, M.; Ikebe, K.; Furuya-Yoshinaka, M. \& Maeda, Y. Prevalence of torus mandibularis among a group of elderly Japanese and its relationship with occlusal force. Gerodontology, 31(2):117-22, 2014.

\section{Corresponding author: \\ Jinling Shao \\ Department of Orthodontics \\ School of Stomatology \\ The Air Force Medical University \\ Xi'an, Shannxi \\ P. R. CHINA}

Email: sususu_su@163.com

Received: 23-06-2021

Accepted: 15-07-2021 